\title{
COMMUTATORS FOR THE MAXIMAL FUNCTIONS ON LEBESGUE SPACES WITH VARIABLE EXPONENT
}

\author{
PU ZHANG AND JiANGLONG WU
}

Abstract. Let $M$ be the Hardy-Littlewood maximal function, the commutator generated by $M$ and a suitable function $b$ is defined by $[M, b] f=M(b f)-b M f$. In this paper, the authors give some characterizations of $b$ for which $[M, b]$ is bounded on the Lebesgue spaces with variable exponent. The similar results are also proved for the commutator of the sharp maximal function.

Mathematics subject classification (2010): 42B25, 46E30.

Keywords and phrases: commutator, BMO, Hardy-Littlewood maximal function, sharp maximal function, Lebesgue space with variable exponent.

\section{REFERENCES}

[1] J. Bastero, M. Milman And F. J. Ruiz, Commutators for the maximal and sharp functions, Proc. Amer. Math. Soc., 128, 11 (2000), 3329-3334.

[2] R. Coifman, R. Rochberg And G. Weiss, Factorization theorems for Hardy spaces in several variables, Ann. Math., 103 (1976), 611-635.

[3] D. CruZ-Uribe, A. Fiorenza, J. Martell And C. PÉrez, The boundedness of classical operators on variable $L^{p}$ spaces, Ann. Acad. Sci. Fenn. Math., 31 (2006), 239-264.

[4] D. Cruz-Uribe, A. Fiorenza And C. J. Neugebauer, The maximal function on variable $L^{p}$ spaces, Ann. Acad. Sci. Fenn. Math., 28 (2003), 223-238.

[5] L. Diening, Maximal function on Musielak-Orlicz spaces and generalized Lebesgue spaces, Bull. Sci. Math., 129 (2005), 657-700.

[6] L. Diening, Maximal function on generalized Lebesgue spaces $L^{p(\cdot)}$, Math. Inequal. Appl., 7, 2 (2004), 245-253.

[7] L. Diening, P. Harjulehto, P. Hästö, Y. Mizuta and T. Shimomura, Maximal functions in variable exponent spaces: limiting cases of the exponent, Ann. Acad. Sci. Fenn. Math. 34, 2 (2009), 503-522.

[8] L. Diening, P. HaRjulehto And P. HÄstÖ, M. RŮŽIČKa, Lebesgue and Sobolev spaces with variable exponents, Lecture Notes in Mathematics 2017, Springer-Verlag, Berlin, 2011.

[9] M. IZUKI, Boundedness of sublinear operators on Herz spaces with variable exponent and application to wavelet characterization, Analysis Mathematica, 36 (2010), 33-50.

[10] M. IZUKI, Boundedness of commutators on Herz spaces with variable exponent, Rend. Circ. Mat. Palermo, 59 (2010), 199-213.

[11] O. KovÁčIK AND J. RÁKosník, On spaces $L^{p(x)}$ and $W^{k, p(x)}$, Czechoslovak Math. J., 41, (4) (1991), 592-618.

[12] A. LERNER, Some remarks on the Hardy-Littlewood maximal function on variable $L^{p}$ spaces, Math. Z., 251, 3 (2005), 509-521.

[13] A. LERNER, On some questions related to the maximal operator on variable $L^{p}$ spaces, Trans. Amer. Math. Soc., 362 (2010), 4229-4242.

[14] M. Milman And T. Schonbek, Second order estimates in interpolation theory and applications, Proc. Amer. Math. Soc., 110, 4 (1990), 961-969.

[15] J. MusielaK, Orlicz spaces and modular spaces, Lecture Notes in Mathematics 1034, SpringerVelag, Berlin, 1983. 
[16] A. NeKvinda, Hardy-Littlewood maximal operator on $L^{p(x)}\left(\mathbb{R}^{n}\right)$, Math. Inequal. Appl., 7 (2004), $255-265$

[17] A. Nekvinda, A note on maximal operator on $\ell^{\left\{p_{n}\right\}}$ and $L^{p(x)}\left(\mathbb{R}^{n}\right)$, J. Funct. Spaces Appl., 5, 1 (2007), 49-88.

[18] A. NeKVINDA, Maximal operator on variable Lebesgue spaces for almost monotone radial exponent, J. Math. Anal. Appl., 337, 2 (2008), 1345-1365.

[19] L. PICK AND M. RŮŽIČKA, An example of a space $L^{p(\cdot)}$ on which the Hardy-Littlewood maximal operator is not bounded, Expo. Math., 19 (2001), 369-371.

[20] J. S. XU, The boundedness of multilinear commutators of singular integrals on Lebesgue spaces with variable exponent, Czechoslovak Math. J., 57 (2007), 13-27.

[21] P. Zhang And J. L. Wu, Commutators for the fractional maximal functions, Acta Math. Sinica (Chinese Series), 52, 6 (2009), 1235-1238. 